\title{
Rancang Bangun Sistem Prediksi Financial Distress Menggunakan Metode Altman Z-Score Modifikasi Pada Koperasi XYZ
}

\author{
Ni Made Lissa Primadani*, Ni Kadek Ariasih** \\ *, **Program Studi Teknik Informatika, STMIK STIKOM Indonesia \\ *lissaprimadani@gmail.com,**kdariasih@ @tiki-indonesia.ac.id
}

\begin{abstract}
Financial distress is a condition in which a company begins to show signs of bankruptcy due to a decline in the company's financial condition. XYZ Cooperative is a savings and loan cooperative that needs to be aware of experiencing financial distress. What's more, the XYZ cooperative has experienced fluctuating asset conditions, even for profit in a certain month, it has experienced a negative or loss condition. Another problem that occurred is the covid-19 pandemic which made it difficult for people to carry out their obligations such as paying credit. This made the XYZ Cooperative's income experience a drastic decline from the previous year. Meanwhile, currently XYZ Cooperative does not have a prediction system or has never predicted financial distress in its company Based on these problems, an idea emerged to design and build a financial distress prediction system at the XYZ Cooperative using the Modified Altman Z-Score method. This model was chosen because the financial ratios used in prediction calculations are in accordance with the financial ratios of the XYZ Cooperative. The final result of this research is the construction of a prediction system using the Altman Z-Score Modification method on the desktop-based XYZ Cooperative. From the 3 years of financial reports that were tested from 2017 to 2019 , the prediction results were at a safe point, namely the $\mathrm{Z}$ value above 2.6 . The calculation results for 2017 is $8.19,2018$ is 8.11 and 2019 is 7.82 . However, the predicted $Z$ value from 2017 to 2019 has decreased, although it is not significant. The accuracy calculation obtained compares the prediction results with the real situation of the cooperative using the average comparison formula and the typer error II formula. Where from the 3 sample data tested, the results of the sample received were 3 with a data error of 0
\end{abstract}

Keyword: Financial Distress, Altman Z-Score Modification, Cooperation

\section{Introduction}

Financial distress adalah kondisi dimana keadaan keuangan suatu perusahaan mulai mengalami penurunan [1]. Koperasi XYZ merupakan salah satu koperasi simpan pinjam yang perlu waspada akan mengalami financial distress. Meskipun penilaian kesehatan keuangan Koperasi XYZ saat ini selalu stabil dari tahun ke tahun, bukan berarti perusahaan tidak mungkin mengalami masalah dalam kondisi keuangan suatu saat nanti. Terlebih lagi koperasi XYZ pernah mengalami kondisi aset yang naik turun bahkan untuk profit pada bulan tertentu pernah mengalami kondisi minus atau rugi. Permasalahan lain yang terjadi yaitu, pandemi covid-19 yang membuat masyarakat sulit melakukan kewajibannya seperti membayar kredit. Hal tersebut membuat pendapatan Koperasi XYZ mengalami penurunan drastis dari tahun sebelumnya. Sementara itu Koperasi XYZ terus memberikan kelonggaran atau permakluman bagi nasabah yang tidak bisa melaksanakan kewajibannya akibat pandemi. Apabila kondisi ini terus terjadi dan tidak ada kewaspadaan, bukan tidak mungkin Koperasi XYZ juga akan mengalami financial distress dan koperasi juga akan sulit melakukan kewajibannya kepada nasabah lain.

Saat ini Koperasi XYZ belum mempunyai sistem prediksi atau belum pernah melakukan prediksi financial distress pada perusahaannya. Untuk mengantisipasi hal yang tidak diinginkan di masa depan seperti penurunan kondisi keuangan atau bahkan kebangkrutan, Koperasi XYZ memerlukan suatu prediksi yang dapat mengukur potensi financial distress dan memberikan early warning. Fungsi early warning sendiri agar koperasi dapat menyiapkan kebijakan-kebijakan seperti kapan seharusnya mulai bertindak tegas dan kapan tetap memberikan kelonggaran pada nasabahnya.

Berdasarkan permasalah tersebut, maka solusi yang diajukan yaitu merancang dan membangun sistem prediksi financial distress menggunakan Metode Altman Z-Score Modifikasi. Model Altman Modifikasi dipilih karena rasio-rasio keuangan yang yang digunakan dalam perhitungannya sesuai dengan rasio keuangan yang dimiliki Koperasi XYZ. Selain itu pembuatan prediksi dalam bentuk sistem diharapkan agar pihak koperasi lebih mudah dalam melakukan perhitungan financial distress, serta dapat digunakan oleh Koperasi XYZ secara terus menerus pada tahun-tahun berikutnya. Sistem yang akan dirancang dan dibangun akan menggunakan perancangan tersetruktur dan pengembangan sistem dengan metode waterfall. Sistem yang 
diminta dalam bentuk desktop ini diharapkan dapat menghasilkan informasi aman atau tidaknya pada laporan keuangan Koperasi XYZ. Informasi yang dihasilkan diharapkan dapat digunakan sebagai acuan untuk menyiapkan kebijakan-kebijakan perusahaan agar dapat mencegah terjadinya financial distress pada Koperasi XYZ.

Adapun batasan-batasan dalam penelitian ini yaitu data yang digunakan sebagai sampel penelitian ini hanya data keuangan Koperasi XYZ dari tahun 2017 sampai 2019. Selain itu, penelitian ini tidak menggunakan uji Hipotesis untuk menghitung akurasi metode, melainkan diganti dengan uji pembanding rata-rata antara prediksi dengan keadaan real koperasi.

Dengan begitu penelitian yang berjudul "Rancang Bangun angun Sistem Prediksi Financial Distress Menggunakan Metode Altman Z-Score Pada Koperasi XYZ” ini bertujuan untuk meningkatkan kewaspadaan dan mencegah terjadinya masalah keuangan pada Koperasi XYZ.

\subsection{Jurnal Yang Terkait}

Ada beberapa penelitian terdahulu telah membahas topik yang sama, sehingga dijadikan acuan serta referensi dalam penelitian ini. Yang pertama adalah penelitian dari kartika yang berjudul Potensi Kebangkrutan Pada Sektor Perbankan Syariah Untuk Menghadapi Lingkungan Bisnis Dengan Menggunakan Model Altman Z-Score Modifikasi[2]. Permasalahan dalam penelitian ini yaitu ketika bank konvensional mengalami kesulitan akibat dari krisis ekonomi. Sementara itu, perbankan syariah tidak terlalu mengalami dampak negatif akibat krisis yang terjadi. Tapi bukan berarti bank syariah tidak akan menghadapi resiko suatu saat nanti. Untuk mengantisipasi resiko tersebut, maka diperlukan tindakan mengukur kondisi keuangannya sedini mungkin. Berdasarkan latar belakang permasalahan tersebut, akhirnya digunakan teknik Multiple Discriminant Analysis (MDA) atau lebih tepatnya model Altman Z-Score Modifikasi untuk mengukur kondisi keuangan pada bank syariah.

Penelitian kedua oleh Jati dan Prasetyo yang berjudul Analisis Potensi Kebangkrutan Bank Umum Syariah Di Indonesia Pada Periode 2012- 2016 Dengan Metode Multiple Discriminant Analysis [3]. Meskipun bank syariah tidak mengalami dampak krisis global namun jika aktivitas ekonomi terus menerus mengalami penurunan, maka bagi hasil syariah menjadi terganggu akibat keuntungan yang sangat kecil. Terlebih lagi persaingan bank syariah semakin ketat akibat banyak bank-bank syariah baru yang bermunculan. Dengan begitu untuk mengukur potensi kebangkrutan pada Bank Umum Syariah, penelitian terdahulu ini menggunakan model altman Z-Score Modifikasi sebagai metode perhitungan.

Penelitian yang ketiga dilakukan oleh Riwoe yang berjudul Analisis Prediksi Kebangkrutan Perusahaan Dengan Altman's Z-Score Modifikasi Dan Pola Arus Kas Pada PT. Bumi Resources Minerals TBK [4]. Permasalahan dalam penelitian ketika PT. Bumi Resources Minerals Tbk mengalami kerugian akibat saham yang diterbitkan tidak laku terjual. Sementara itu saham yang diterbitkan sebesar Rp 8,04 triliun atau USD 700 juta dengan jumlah sebanyak 32,19 miliar lembar. Dibalik itu PT. Bumi Resources Minerals Tbk memiliki sejumlah hutang yang belum dapat terbayarkan sementara harga saham terus merosot. Hal inilah yang menyebabkan tingkat keuangan PT. Bumi Resources Minerals Tbk mengalami penurunan. Dengan permasalahan yang ada, penelitian terdahulu ini melakukan analisa kebangkrutan pada PT. Bumi Resources Minerals Tbk menggunakan Altman's Z-Score Modifikasi serta membandingkan dengan kondisi arus kasnya.

Penelitian keempat dilakukan oleh Aksad dkk yang berjudul Aplikasi Prediksi Kebangkrutan Perusahaan Dengan Menggunakan Metode Z-Score Berbasis Web [5]. Penelitian ini membahas bagaimana resiko kebangkrutan dapat dilihat melalui laporan keuangan. Salah satu metode yang dapat digunakan untuk mengukur tingkat kebangkrutan perusahaan adalah Metode Altman Z-Score. Dalam penelitian terdahulu yang disebutkan oleh Aksad dkk, penelitian dilakukan masih secara manual atau proses penilaian dilakukan secara konvensional. Dengan begitu Aksad dkk melakukan penelitian untuk merancang sistem informasi berbasis web sebagai media untuk membantu memprediksi kebangkrutan perusahaan yang terdaftar pada BEI.

Penelitian terakhir dilakukan oleh fitriani dan Santosa yang berjudul Application of Altman Modified Z-Score to Predict Financial Distress in the Indonesian Telecommunications Industry [6]. Pada peneliyian ini membahas bagaimana pengaplikasian Metode Altman Z-Score Modifikasi pada beberapa perusahaan telekomunikasi Indonesia untuk mengathui prospek ke depan dari perusahan-perusahaan tersebut. 


\subsection{Model Altman Z-Score Modifikasi (Altman Z'-Score)}

Altman Z-Score merupakan teknik statikstik yang digunakan untuk memprediksi kebangkrutan dengan mengandalkan rasio-rasio keuangan. Metode ini dikembangkan oleh peneliti kebangsaan Amerika Edward I.Altman pada pertengahan 1960 [7].

Altman Z-Score sendiri mempunyai tiga model perhitungan. Yang pertama adalah model Altman ZScore Original (Pertama), dimana model ini dicetuskan untuk perusahaan manufaktur yang go public. Selanjutnya model Altman Z-Score kembali mengalami revisi agar dapat dipakai oleh perusahaan sektor-sektor swasta yang tidak go public. Model Altman yang kedua ini kemudian dikenal dengan Model Altman Z-Score Revisi atau Altman Z'-Score. Model ketiga yang berkembang adalah model Altman Z-Score Modifikasi (Altman Z"'-Score). Mengingat tidak semua perusahaan memiliki rasio yang sama seperti perusahaan manufaktur, model modifikasi ini sengaja dikembangkan agar dapat digunakan oleh semua jenis perusahaan baik itu manufaktur atau pun non manufaktur dan perusahaan go public maupun yang non public. Model Modifikasi ini berbeda dengan kedua model sebelumnya, dimana terletak jumlah penggunaan rasio. Dua model sebelumnya menggunakan 5 rasio sementara model terakhir hanya menggunakan 4 jenis rasio.

Menurut Supardi, Altman mengeliminasi variable $\mathrm{X}_{5}$ (sales to total asset), karena rasio ini sangat bervariatif pada industri dengan ukuran aset yang berbeda-beda. Supardi [8]. Adapun rumus dari model Altman Modifikasi adalah sebagai berikut [9]:

a. Rumus model Altman Z-Score Modifikasi dapat dilihat pada persamaan 1.

$$
Z=6,56 X_{1}+3,26 X_{2}+6,72 X_{3}+1,05 X_{4}
$$

Keterangan

$\mathrm{Z}=$ Indeks Kebangkrutan

$\mathrm{X}_{1}=$ Modal Kerja/Total Aset

$\mathrm{X}_{2}=$ Laba Ditahan/Total Aset

$\mathrm{X}_{3}=$ Pendapatan Sebelum Bunga dan Pajak/Total Aset

$\mathrm{X}_{4}=$ Nilai Buku Ekuitas/Nilai Buku Hutang

b. Nilai Cutt-Off dapat dilihat seperti pada Tabel 1.

Tabel 1. Nilai Cutt-Off Z-Score Modifikasi

\begin{tabular}{|l|l|}
\hline $\mathrm{Z}<1.1$ & Bangkrut \\
\hline $1.1<\mathrm{Z}<2.6$ & Rawan \\
\hline $\mathrm{Z}>2.6$ & Aman \\
\hline
\end{tabular}

\subsection{Penilaian Kesehatan Koperasi}

Penilaian kesehatan adalah penelian yang dilakukan kepada koperasi dengan meninjau beberapa aspek yang dianggap berpengaruh terhadap kesehatan koperasi. Aspek yang berpengaruh diantaranya manajemen, permodalan, kualitas aktiva produktif, efisiensi, kemandirian dan pertumbuhan. Serta tak lupa menilai dari segi likuiditas dan jati diri koperasi. Adapun tingkap kesehatan pada koperasi simpan pinjam dapat dilihat pada Tabel 2 [10].

Tabel 2. Tingkat Kesehatan Koperasi

\begin{tabular}{|l|l|}
\hline \multicolumn{1}{|c|}{ Skor } & \multicolumn{1}{c|}{ Predikat } \\
\hline $80<X<100$ & Sehat \\
\hline $60<X<80$ & Cukup Sehat \\
\hline $40<X<60$ & Kurang Sehat \\
\hline $20<X<40$ & Tidak Sehat \\
\hline$<20$ & Sangat Tidak Sehat \\
\hline
\end{tabular}




\section{Research Method}

Adapun metode-metode pengumpulan data yang digunakan dibagi berdasarkan sifat datanya, yaitu data primer dan data sekunder.

\subsection{Data Primer}

Metode pengumpulan data primer yang peneliti lakukan yaitu dengan melakukan Wawancara langsung dengan pihak Koperasi XYZ. Pada tahap ini narasumber menjelaskan bagaimana pendapatan pada koperasi yang bisa naik turun dan tidak menentu. Sehingga menemukan permasalahan bahwa pada koperasi belum ada prediksi financial distress untuk memberikan warning akibat naik turunnya pendapatan perusahaan. Serta dilakukan observasi yang bertujuan untuk mengamati kondisi yang terjadi pada rasio-rasio keuangan pada Koperasi XYZ.

\subsection{Data Sekunder}

Data Sekunder adalah data yang digunakan untuk melengkapi data primer. Adapun data sekunder yang digunakan dalam penelitian ini berupa dokumentasi rasio keuangan yang akan digunakan sebagai sampel perhitungan pada penelitian ini. Rasio keuangan dari Koperasi XYZ dapat dilihat pada Tabel 3.

Tabel 3. Rasio Keuangan Koperasi XYZ

\begin{tabular}{|c|c|c|c|c|}
\hline \multicolumn{5}{|c|}{ Rasio Keuangan Koperasi XYZ } \\
\hline Rasio & 2017 & & 2018 & 2019 \\
\hline Modal Kerja & Rp. 1.722.761.962 & $\mathrm{Rp}$ & $, 350,101,175$ & Rp 2,600,991,823 \\
\hline Total Aset & Rp. 1.816.081.208 & $\mathrm{Rp}$ & ,421,905,672 & Rp 2,827,488,041 \\
\hline Laba Ditahan & Rp. 33.432.608 & $\mathrm{Rp}$ & $87,850,575$ & $94,741,746$ \\
\hline Pendapan SPB & Rp. 444.084 .963 & $\mathrm{Rp}$ & $466,501,830$ & $570,260,899$ \\
\hline Nilai Ekuitas & Rp. 343.792.001 & $\mathrm{Rp}$ & $582,254,916$ & $667,817,178$ \\
\hline Nilai Buku Hutang & Rp. 1.391.255.202 & $\mathrm{Rp}$ & $, 839,650,756$ & Rp 2,159,670,863 \\
\hline
\end{tabular}

\section{Result and Analysis}

Adapun hasil dari analisis yang telah dilakukan adalah sebagai berikut:

\subsection{Perhitungan Prediksi}

Berikut merupakan rumus Altman Z-Score Modifikasi yang akan digunakan :

$$
Z=6,56 X_{1}+3,26 X_{2}+6,72 X_{3}+1,05 X_{4}
$$

Berdasarkan rumus tersebut, maka dilakukan perhitungan menggunakan rasion keuangan koperasi XYZ. Untuk mendapatkan nilai z-score akan ada tiga kali perhitungan, dimana perhitungan yang pertama untuk menentukan nilai X1, X2, X3 dan X4. Adapun hasil perhitungan pertama dapat dilihat pada Tabel 4.

Tabel 4. Perhitungan Pertama (Menentukan Nilai X)

\begin{tabular}{|l|l|l|l|}
\hline \multicolumn{4}{|c|}{ Perhitungan Pertama (Menentukan Nilai X) } \\
\hline Rumus & 2017 & 2018 & 2019 \\
\hline X1 = Modal kerja / Total Aset & 0,95 & 0.97 & 0.92 \\
\hline X2 = Laba Ditahan / Total Aset & 0,02 & 0.04 & 0.03 \\
\hline X3 = Pendapatan SPB / Total Aset & 0,24 & 0.19 & 0.20 \\
\hline X4 = Nilai Ekuitas/ Nilai Buku Hutang & 0,25 & 0.32 & 0.31 \\
\hline
\end{tabular}


Setelah mendapatkan nilai X berdasarkan tabel di atas, maka selanjutnya mengalikan seluruh nilai X dengan nilai pengali yang sudah ditentukan pada rumus z-score modifikasi. Adapun hasil perhitungan kedua dapat dilihat pada Tabel 5.

Tabel 5. Perhitungan Kedua (Menentukan Score dari X)

\begin{tabular}{|c|c|c|c|}
\hline \multicolumn{4}{|c|}{ Perhitungan Kedua (Menentukan Score dari X) } \\
\hline Rumus & 2017 & 2018 & 2019 \\
\hline X1(6.56) & 6,22 & 6.37 & 6.03 \\
\hline X2(3.26) & 0,06 & 0.12 & 0.11 \\
\hline X3(6.72) & 1,64 & 1.29 & 1.36 \\
\hline X4(1.05) & 0,26 & 0.33 & 0.32 \\
\hline
\end{tabular}

Setelah mendapatkan nilai seperti tabel di atas, maka selanjutnya menjumlahkan seluruh score pada table di atas. Adapun hasil perhitungan ketiga dapat dilihat pada Tabel 6.

Tabel 6. Perhitungan Ketiga (Menentukan Score dari X)

\begin{tabular}{|l|c|c|c|}
\hline \multicolumn{4}{|c|}{ Perhitungan ketiga (Hasil Prediksi) } \\
\hline \multicolumn{1}{|c|}{ Keterangan } & 2017 & 2018 & 2019 \\
\hline Nilai Z-Score & 8,19 & 8,11 & 7,82 \\
\hline Nilai Cutt Off & Aman & Aman & Aman \\
\hline
\end{tabular}

\subsection{Uji Perbandingan Perhitungan Prediksi Dengan Keadaan Real Koperasi}

Dalam penelitian Wahyuni dan Suriyanti, ada cara pengujiam yang dapat digunakan untuk menentukan akurasi metode Altman Z-Score Modfikasi yaitu Uji Hipotesis Secara Parsial. Dalam penelitiannya, Wahyuni dan Suriyanti menggunakan 20 data perbankan yang terdaftar dalam BEI untuk melakukan Uji Hipotesis, sehingga menemukan tingkat akurasi Altmat Z-Score sebesar 60\% [11].

Yang kedua adalah penelitian yang dilakukan oleh Winarso, juga menggunakan Uji Hipotesis untuk mengetahui akurasi metode Altman Z-Score Modifikasi. Uji Hipotesis yang dilakukan Winarso menggunakan 13 sampel perusahaan Manufaktur yang tercatat di BEI. Meskipun dalam jurnal yang diunggah tidak dicantumkan berapa tingkat akurasinya, tapi Winarso jelas mencantumkan Uji Hipotesis sebagai pengujian ketepatan prediksi financial distress menggunakan metode-metode yang ia gunakan [12].

Menurut penelitian yang dilakukan oleh Pratiwi dkk, untuk menghitung tingkat akurasi metode Altman Z-Score dapat dilakukan dengan menghitung perbandingan tipe error II terhadap data sampel yang digunakan. Tipe error II sendiri merupakan kesalahan yang terjadi jika model memprediksi objek penelitian bangkrut tetapi kenyataannya tidak bangkrut [13]. Sementara itu dalam penelitian yang dilakukan oleh Hastuti, juga membahas rumus perbandingan yang sama dapat dilihat pada Persamaan 2 dan Persamaan 3.

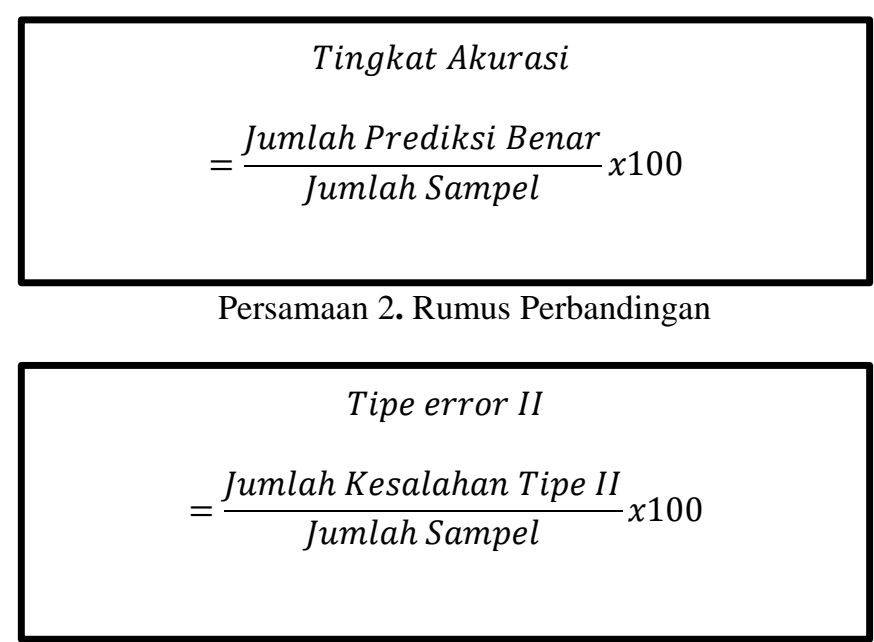

Persamaan 3. Rumus Tipe Error 
Dilihat dari penelitian sebelumnya maka Uji Hipotesis belum dilakukan karena keterbatasan data sampel yang dimiliki saat ini. Namun untuk mengetahui prediksi dapat diterima atau tidak berdasarkan sampel data yang diberikan oleh Koperasi XYZ, maka dilakukan perhitungan menggunakan rumus perbandingan dan rumus tipe error.

Untuk menentukan prediksi diterima atau tidak, maka dilakukan perbandingan prediksi dengan keadaan real koperasi XYZ. Adapun penggolongan yang dilakukan dengan menggunakan penilaian tingkat kesehatan Koperasi XYZyang dapat dilihat pada Tabel 7.

Tabel 7. Penggolongan Akurasi

\begin{tabular}{|l|l|l|}
\hline Kesehatan Koperasi & Hasil Prediksi & Keteragan \\
\hline Sehat & Aman & Diterima \\
\hline Cukup Sehat & Aman & Diterima \\
\hline Kurang Sehat & Rawan & Diterima \\
\hline Tidak Sehat & Bangkrut & Diterima \\
\hline Sangat Tidak Sehat & Bangkrut & Diterima \\
\hline
\end{tabular}

Sesuai dengan perhitungan prediksi pada tahun 2017-2019 yang menyatakan keadaan koperasi digolongkan aman, serta penilaian tingkat Koperasi XYZ pada tahun 2018-2020 yang mendapatkan nilai "Cukup Sehat", maka hasil perbandingan dapat dilihat pada Tebel 8.

Tabel 8. Hasil Perbandingan

\begin{tabular}{|l|l|l|l|l|}
\hline \multicolumn{2}{|l|}{ Hasil Prediksi } & \multicolumn{2}{l|}{ Kesehatan Koperasi } & Hasil \\
Tahun & Keterangan & Tahun & Keterangan & Dingan \\
\hline 2017 & Aman & 2018 & Cukup Sehat & Diterima \\
\hline 2018 & Aman & 2019 & Cukup Sehat & Diterima \\
\hline 2019 & Aman & 2019 & Cukup Sehat & Diterima \\
\hline
\end{tabular}

Selanjutnya adalah proses menghitung berapa persen jumlah prediksi yang diterima dan jumlah prediksi yang masuk tipe error. Berdasarkan rumus yang dicantumkan Pratiwi dkk, maka persentase perbandingan dapat dilihat pada Persamaan 4 dan Persamaan 5.

Tingkat Akurasi $=\frac{3}{3} x 100=100 \%$

Persamaan 4. Perhitungan Perbandingan

$$
\text { Tipe Error } I I=\frac{0}{3} x 100=0 \%
$$

Persamaaan 5. Perhitungan Tipe Error

Dilihat perhitungan tingkat akurasi prediksi menggunakan 3 tahun data sampel pada Koperasi XYZ, dapat diterima ketiganya dengan tingkat tipe error sebesar 0 data. Dengan begitu perhitungan prediksi financial distress menggunakan Metode Altman Z-Score Modifikasi dapat diterima pada Koperasi XYZ.

Namun berdasarkan penelitian yang dilakukan oleh Pratiwi dkk, dimana dengan rumus yang sama Pratiwi dkk mendapatkan 4 prediksi yang diterima dari 5 sampel data yang diujikan. Dengan begitu akurasi yang didapatkan Pratiwi dkk sebesar 80\% dengan tingkat tipe error II sebesar 20\% [13]. Dengan perbedaan tingkat akurasi yang didapatkan dari penelitian ini dangan penelitian sebelumnya, dapat disimpulkan rumus perbandingan tingkat akurasi bergantung pada jumlah prediksi yang diterima pada sampel yang diujikan.

\subsection{Perancangan Sistem}

Dalam perancangan sistem, penulis menggunakan metode perancangan sistem terstruktur yang akan dijabarkan dengan pembuatan Context Diagram dan Data Flow Diagram Level 0.

\section{A. Context Diagram}

Context Diagram merupakan diagram yang dapat menggambarkan keseluruhan Sistem Prediksi Financial Distress pada Koperasi XYZ. Adapun context diagram pada penelitian ini dapat dilihat pada Gambar 1. 


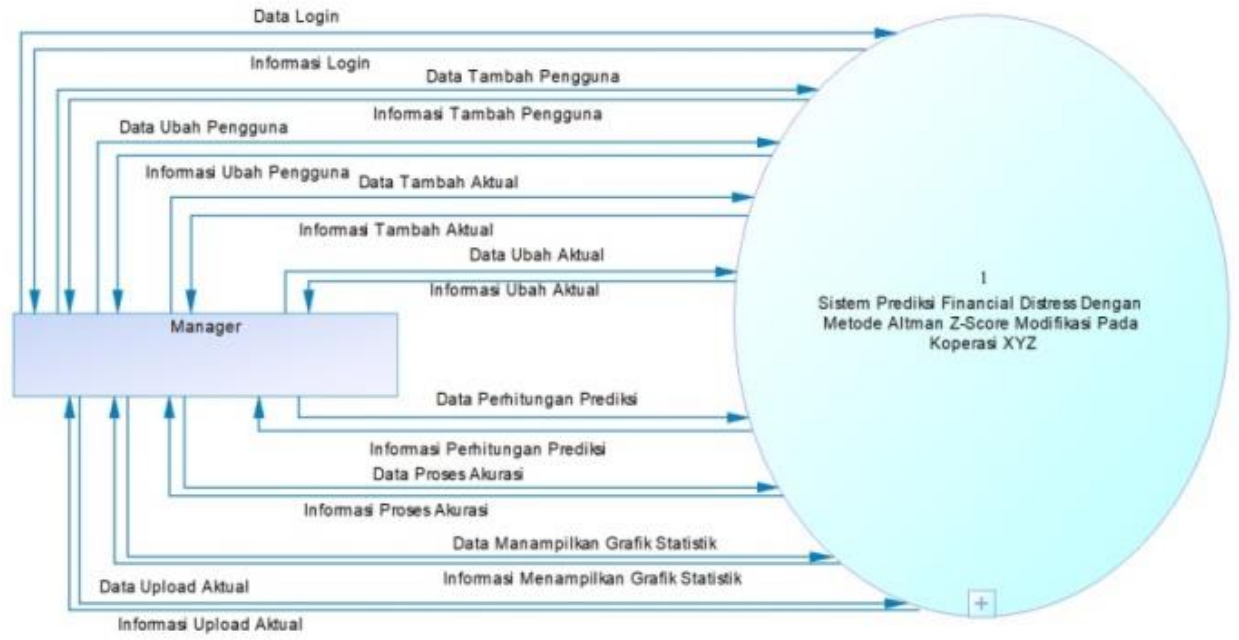

Gambar 1. Context Diagram

\section{B. Data Flow Diagran Level 0}

Data flow diagram level 0 menjelaskan alur dari masing-masing proses yang berjalan. Perancangan sistem prediksi financial distress terdiri dari empat proses yaitu, login, mengelola data pengguna, mengelola data aktual dan mengelola prediksi. Data flow diagram level pada penelitian ini dapat dilihat pada Gambar 2.

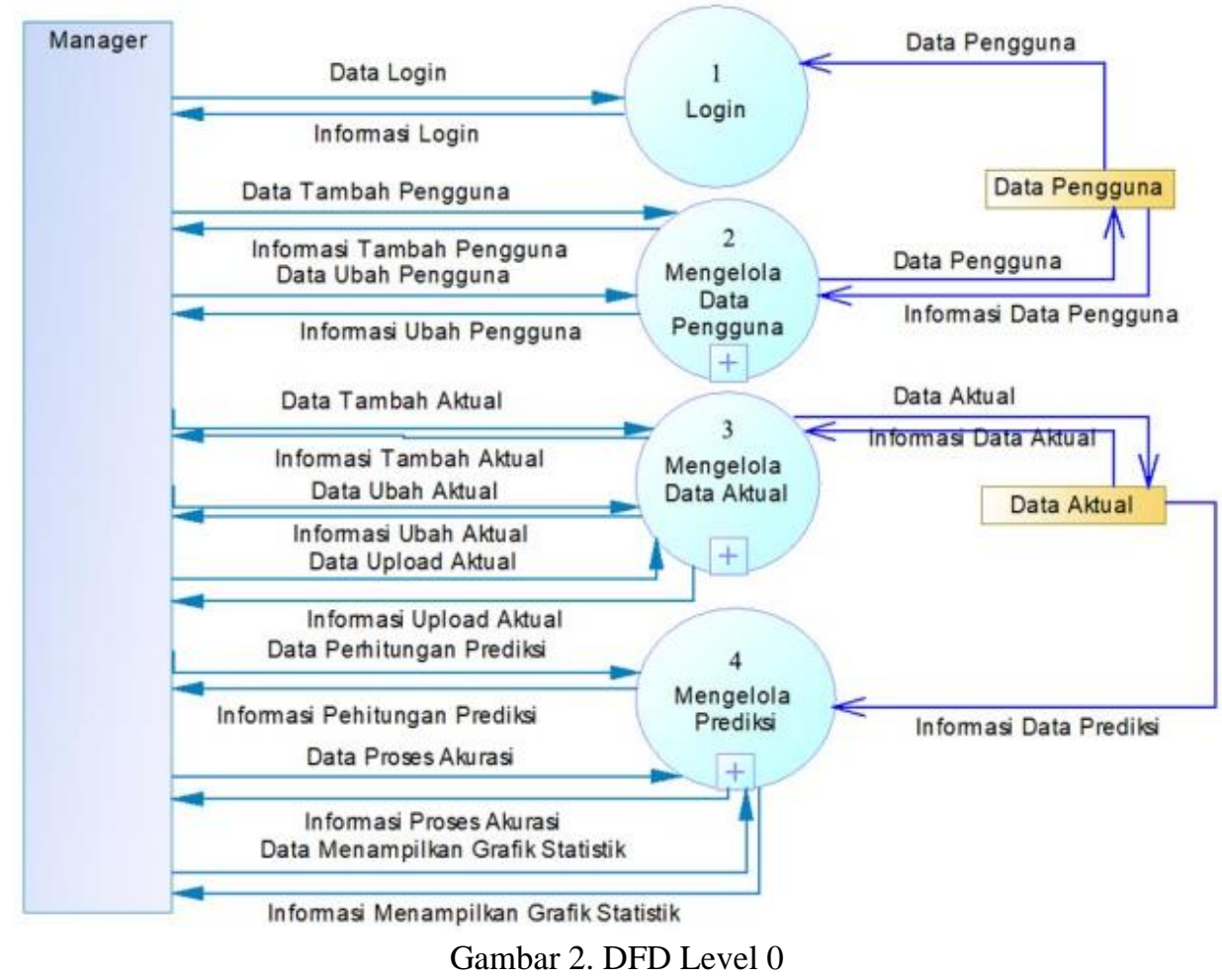

\subsection{Implementasi Sistem}

Implementasi sistem merupakan hasil dari analisis dan perancangan yang telah dibuat. Yang pertama ada halaman data aktual. Dimana pada halaman ini sudah terlihat list data aktual, tombol import data, tambah dan edit data, tombol prediksi, tombol statistik dan tombol cetak laporan prediksi. Impementasi perhitunga prediksi pada sistem dapat dilihat pada gambar 3. Implementasi data aktual pada sistem dapat dilihat pada Gambar 3. 


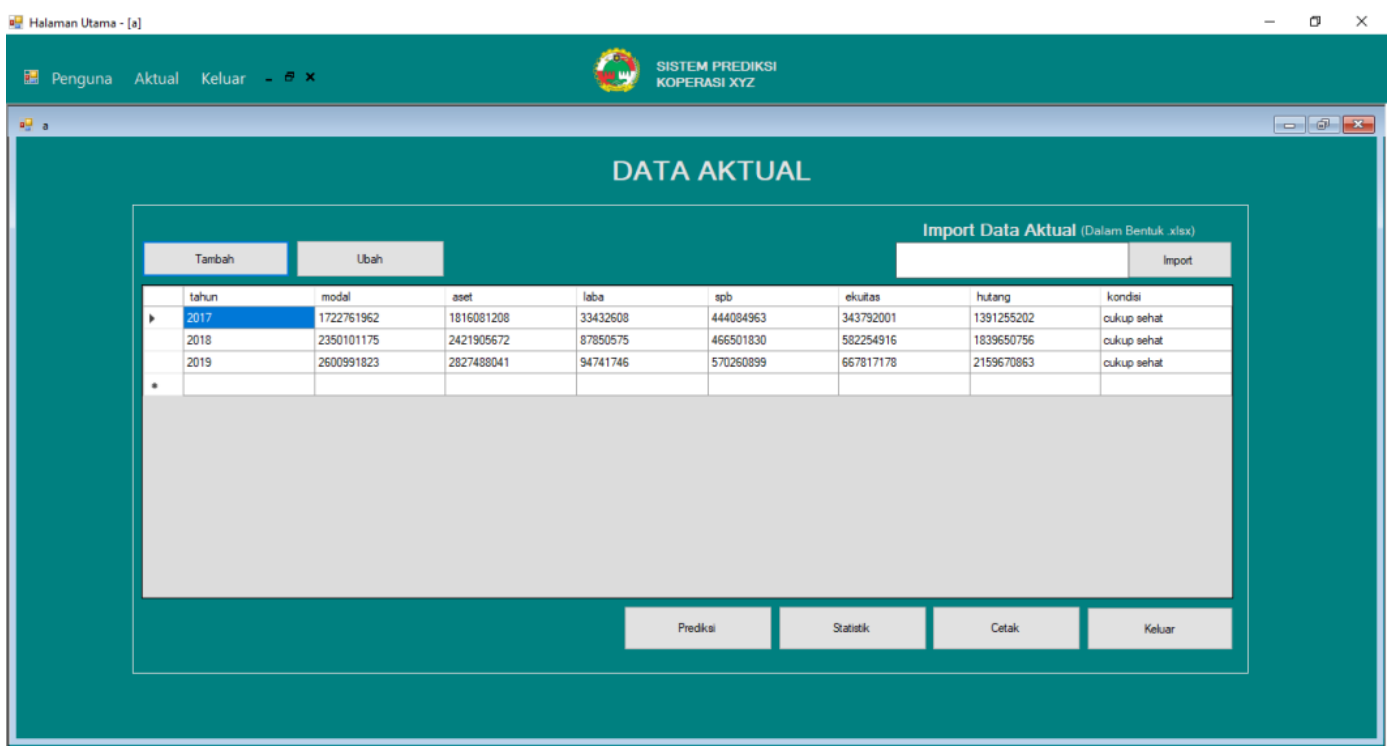

Gambar 3. Halaman List Data Aktual

Untuk mengelola prediksi, user harus masuk pada halaman aktual terlebih dahulu. Pada halaman aktual, manager dapat menekan tombol prediksi untuk melihat form perhitungan prediksi. Pada form prediksi manager dapat melakukan proses cari data aktual, proses hitung dan akurasi prediksi. Implementasi perhitungan prediksi pada sistem dapat dilihat pada Gambar 4.

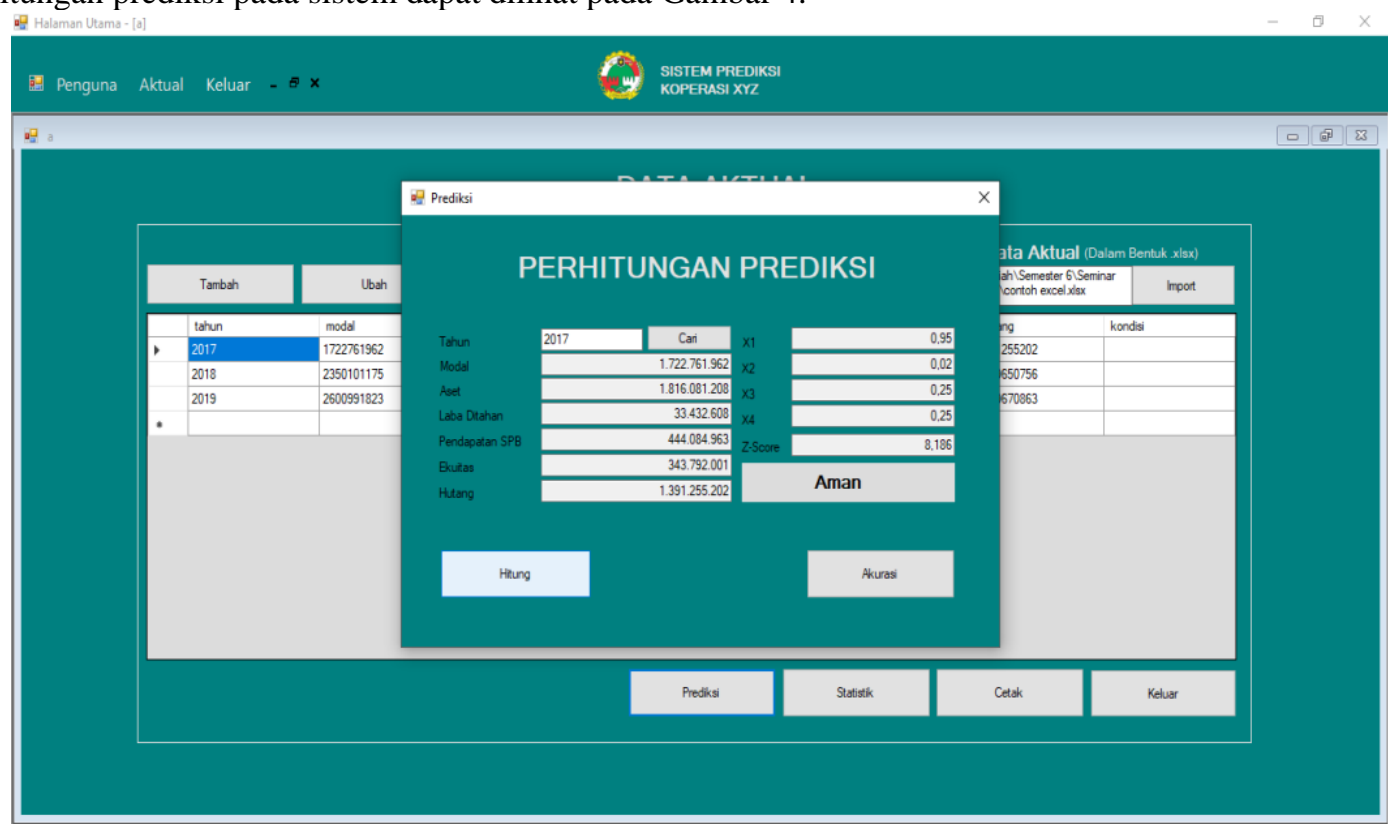

Gambar 4. Halaman Form Prediksi

Untuk melakukan akurasi, user hanya perlu menekan tombol akurasi setelah melakukan perhitungan prediksi. Proses akurasi ini berfungsi untuk melihat perbandingan prediksi dengan kesehatan koperasi sebenarnya, Implementasi perhitungan akurasi pada sistem dapat dilihat pada Gambar 5. 


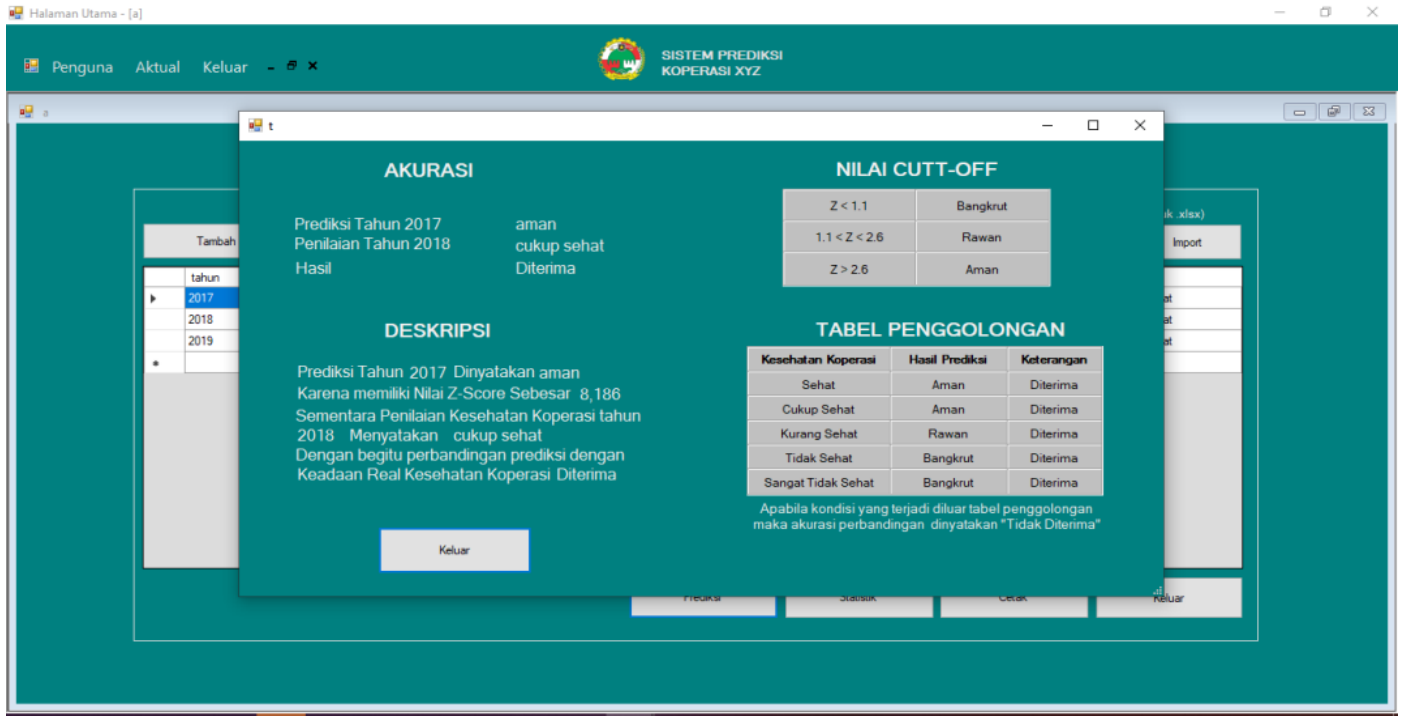

Gambar 5. Halaman Proses Akurasi

\section{Conclusion}

Berdasarkan penelitian Sistem Prediksi Financial Distress Menggunakan Metode Altman Z-Score Modifikasi Pada Koperasi XYZ, dapat diambil kesimpulan bahwa:

1. Penerapan Metode Altman Z-Score Modifikasi terhadap laporan keuangan koperasi XYZ menggunakan laporan keuangan tahun 2017 sampai 2019 mendapatkan hasil prediksi berada pada titik aman yaitu nilai Z diatas 2,6. Untuk hasil perhitungan tahun 2017 adalah 8.19, tahun 2018 adalah 8.11 dan tahun 2019 adalah 7.82. Namun nilai Z prediksi dari tahun 2017 sampai 2019 mengalami penurunan meskipun tidak signifikan.

2. Untuk menghitung akurasi, saat ini belum dilakukan dengan pengujian Hipotesis mengingat keterbatasan data sampel yang dimiliki saat ini hanya satu perusahaan, sementara penelitian terdahulu yang menggunakan uji hipotesis menggunakan data lebih dari satu perusahaan. Dengan begitu uji hipotesis diganti dengan membandingkan hasil prediksi dengan keadaan real koperasi menggunakan rumus perbandingan rata-rata dan rumus typer error II. Dimana dari 3 data sampel yang diujikan, mendapatkan hasil sampel yang diterima sebesar 3 dengan data error sebesar 0 .

\section{References (10 PT)}

[1] E. D. Fahlevi and H. Mukhibad, "Penggunaan Rasio Keuangan Dan Good Corporate Governance Untuk Memprediksi Financial Distress," J. Reviu Akunt. dan Keuang., vol. 8, no. 2, pp. 147-158, 2018.

[2] S. P. Kartika, "Potensi Kebankrutan Pada Sektor Perbankan Syariah Untuk Menghadapi Perubahan Lingkungan Bisnis Dengan Menggunakan Model Altman Z-Score Modifikasi (Studi Bank Umum Syariah di Indonesia Periode 2010-2014)," pp. 1-97, 2015.

[3] R. P. Jati and S. E. M. S. Dr. Ari Prasetyo, "Analisis Potensi Kebangkrutan Bank Umum Syariah Di Indonesia Pada Periode 2012- 2016 Dengan Metode Multiple Discriminat Analysis,” Ekon. Syariah Teor. dan Terap., vol. 5, no. 11, pp. 941-958, 2018.

[4] J. C. Riwoe, “Analisis Prediksi Kebangkrutan Perusahaan Dengan Altman's Z-Score Modifikasi Dan Pola Arus Kas Pada PT. Bumi Resources Minerals TBK.,” Account. Bus. Stud., vol. 1, no. 2, pp. 115, 2017.

[5] H. Aksad, S. Natarsyah, and M. Rizky, “Aplikasi Prediksi Kebangkrutan Perusahaan Dengan Menggunakan Metode Z-Score Berbasis WEB,” vol. 1, 2017.

[6] R. Fifriani and P. W. Santosa, “Application of Altman Modified Z-Score to Predict Financial Distress in the Indonesian Telecommunications Industry," J. Econ. Bus. Aseanomics, vol. 4, no. 1, pp. 23-34, 2019.

[7] R. D. W.Tambunan and M. G. W. E. N.P, “Analisis Prediksi Kebangkrutan Perusahaan Dengan Menggunakan Metode Altman (Z-Score) (Studi Pada Subsektor Rokok Yang Listing Dan Perusahaan Delisting Di Bursa Efek Indonesia Tahun 2009 - 2013)," J. Adm. Bisnis, vol. 2, no. 1, pp. 1-11, 2015.

[8] E. Oktarina, “Analisis Prediksi Kebangkrutan Dengan Metode Altman Z-Score Pada PT. BRI SYARIAH,” pp. 1-54, 2017. 
[9] M. S. . Dewi Laela Hilyatin, S.E. and E. Prasdiwi, "Analisis Prediksi Potensi Kebangkrutan Pada PT Bank Muamalat Indonesia TBK Periode 2012-2016 Dengan Menggunakan Metode Altman Modifikasi,” Ekon. Islam, vol. 5, no. 2, p. 302, 2017.

[10] H. G. Soedarsa and D. Natalia, "Analisis Tingkat Kesehatan Koperasi Pada Koperasi Simpan Pinjam Di Kabupaten Tulang Bawang Barat,” Akunt. Keuang., vol. 7, no. 2, 2016.

[11] D. Wahyuni and L. H. Suriyanti, "Prediksi Financial Distress Dengan Altman Modifikasi Dan Springate Pada Perbankan Di Bursa Efek Indonesia Tahun 2015-2017,” Akunt. Ekon., vol. 8, no. 2, 2018.

[12] E. Winarso, "Perbandingan Analisis Model Z"-Score Altman Modifikasi, Model X-Score Zmijewski, Model G-Score Grover, Dan Model S-Score Springate Untuk Menganalisis Ketepatan Prediksi Kebangkrutan (Studi Pada Perusahaan Manufaktur Sektor Industri Pelengkap Otomotif Yang,” vol. 1, no. 2, 2019.

[13] L. Pratiwi, M. Dheasey Amboningtyas, SE, and M. Azis Fathoni, SE, "Analisis Laporan Keuangan Dengan Menggunakan Model Altman ZScore dan Springate Dalam Memprediksi Kebangkrutan (Studi Pada Perusahaan Kosmetik yang Terdaftar di IDX Pada Tahun 2013-2017)," Management, vol. 5, no. 5, 2019. 